\title{
APLIKASI PENCARIAN JALUR TERPENDEK PADA RUMAH SAKIT UMUM BAHTERAMAS MENGGUNAKAN ALGORITMA A* (A-STAR)
}

\author{
${ }^{\# 1}$ Muh. Yamin, ${ }^{\# 2}$ Moh. Bandrigo Talai \\ ${ }^{\# 1,2}$ Jurusan Teknik Informatika, FTEKNIK UHO, Kendari
}

\begin{abstract}
Abstrak
Pencarian jalur terpendek merupakan suatu permasalahan yang sering terjadi pada pengunjung rumah sakit untuk menemukan gedung atau ruangan yang dicari. Salah satu contohnya adalah pada Rumah Sakit Umum Bahteramas. Karena banyaknya gedung dan ruangan yang ada pada rumah sakit tersebut, mengakibatkan pengunjung kesulitan menemukan gedung dan ruangan yang dicari. Oleh karena itu dibutuhkan sistem yang dapat menunjukkan lokasi gedung dan ruangan beserta jalur terpendeknya, agar waktu pencarian lebih efisien. Terdapat beberapa algoritma pencarian jalur terpendek, salah satunya adalah algoritma $A^{*}$ (A-Star). Algoritma $A^{*}$ menggunakan estimasi jarak terdekat untuk mencapai tujuan (goal) dan memiliki nilai heuristik yang digunakan sebagai dasar pertimbangan. Heuristik adalah kriteria, metoda, atau prinsip-prinsip untuk menentukan pilihan sejumlah alternatif untuk mencapai sasaran dengan efektif. Hasil pada penelitian ini adalah aplikasi yang dapat menentukan jalur terpendek antara gedung dan antara ruangan yang diimplementasikan pada Operating System Android dan dibangun dengan menggunakan bahasa pemrograman Actionscript 3.
\end{abstract}

Kata kunci : algoritma A* (A-Star), android, actionscript 3, jalur terpendek.

\section{PENDAHULUAN}

Rumah sakit sebagai salah satu organisasi sektor publik yang bergerak dalam bidang pelayanan jasa kesehatan merupakan organisasi yang sangat penting bagi masyarakat. Sebagai organisasi yang sangat dibutuhkan masyarakat, pelayanan yang diberikan rumah sakit tentunya sangat banyak mulai dari pengobatan, perawatan, dan lain sebagainya sehingga rumah sakit harus memiliki banyak ruangan yang akan digunakan untuk pelayanan kesehatan tersebut.

Sulawesi Tenggara khususnya Kota Kendari, rumah sakit telah banyak dibangun untuk memberikan pelayanan kesehatan kepada masyarakat Kota Kendari. Salah satu rumah sakit yang berada di Kota Kendari yaitu Rumah Sakit Umum Bahteramas. Rumah sakit ini memiliki beberapa gedung yang digunakan untuk kegiatan pelayanan rumah sakit seperti gedung administrasi, gedung IGD (Instalasi Gawat Darurat), gedung rawat inap, gedung bersalin, dan gedung-gedung lainnya. Masing-masing gedung juga memiliki beberapa ruangan dengan fungsi berbeda-beda. Karena banyaknya gedung dan ruangan, belum adanya sistem yang memberi petunjuk lokasi serta jalur tependek menuju gedung dan ruangan membuat pengunjung membutuhkan waktu yang cukup lama untuk menemukan gedung dan ruangan yang dicari. Bertanya kepada orang lain atau petugas rumah sakit menjadi cara untuk memperoleh informasi tentang lokasi ruangan yang dicari.

Untuk mengatasi permasalahan pencarian ruangan yang memerlukan waktu cukup lama, diperlukan sistem yang dapat menunjukkan lokasi serta menentukan jalur terpendek menuju ruangan yang dicari. Teknik pencarian yang sering digunakan untuk menentukan jalur terpendek yaitu pencarian buta (blind search) dan pencarian heuristik (heuristic search). Pencarian buta cenderung lebih mudah dipahami dibandingkan pencarian heuristik, tetapi hasil pencarian yang diperoleh pencarian heuristic lebih variatif dan waktu pencarian solusi lebih cepat. Salah satu metode pencarian jalur terpendek yang termasuk dalam pencarian heurisitc adalah Algoritma A*. Untuk mencapai tujuan dengan jarak tempuh terdekat, Algoritma $\mathrm{A} *$ memiliki suatu nilai heuristik yang digunakan sebagai dasar pertimbangan dimana estimasi nilai/biaya terkecil yang akan menentuan jarak tempuh terdekat. Berdasarkan hal-hal di atas, 
maka dalam hal ini penulis ingin membuat Aplikasi Pencarian Jalur Terpendek Menuju Ruangan pada Rumah Sakit Umum Bahteramas Menggunakan Algoritma A*.

\section{METODE PENELITIAN}

\subsection{Lintasan Terpendek (Shortest Path)}

Lintasan Terpendek (Shortest Path) merupakan lintasan minimum yang diperlukan untuk mencapai suatu titik dari titik tertentu. Dalam pencarian lintasan terpendek masalah yang dihadapi adalah mancari lintasan mana yang akan dilalui sehingga didapat lintasan yang paling pendek dari satu verteks ke verteks yang lain.

Ada beberapa macam persoalan lintasan terpendek, antara lain : (Pawitri, dkk., 2007)

- Lintasan terpendek antara dua buah verteks.

- Lintasan terpendek antara semua pasangan verteks.

- Lintasan terpendek dari verteks tertentu ke semua verteks yang lain

- Lintasan terpendek antara dua buah verteks yang melalui beberapa verteks tertentu.

\subsection{Graph}

\section{2.1Definisi Graph}

Graph adalah kumpulan simpul (nodes) yang dihubungkan satu sama lainmelalui sisi/busur (edges) (Zakaria, 2006). Suatu Graf G terdiri dari dua himpunan yaitu himpunan $\mathrm{V}$ dan himpunan $\mathrm{E}$.

a. $\quad$ Verteks (simpul) $: \mathrm{V}=$ himpunan simpul yang terbatas dan tidak kosong.

b. $\quad$ Edge (sisi/busur): $\mathrm{E}=$ himpunan busur yang menghubungkan sepasangsimpul.

Dapat dikatakan graf adalah kumpulan dari simpul-simpul yang dihubungkan oleh sisi-sisi.

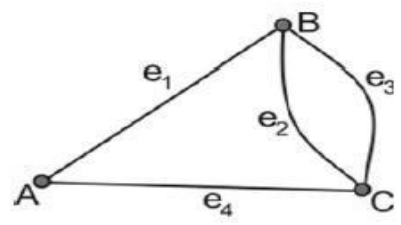

\section{Gambar 2.1 Graf G}

Gambar 2.1 menunjukkan graf terdiri dari himpunan V dan E dimana:

$$
\begin{aligned}
& \mathrm{V}=\{\mathrm{A}, \mathrm{B}, \mathrm{C}\} \\
& \mathrm{E}=\{\mathrm{e} 1, \mathrm{e} 2, \mathrm{e} 3, \mathrm{e} 4\} \\
& =\{(\mathrm{A}, \mathrm{B}),(\mathrm{B}, \mathrm{C}),(\mathrm{B}, \mathrm{C}),(\mathrm{A}, \mathrm{C})\}
\end{aligned}
$$

\subsubsection{Macam -macam graph}

Menurut arah dan bobotnya, graf dibagi menjadi empat bagian, yaitu :

1. Graf berarah dan berbobot : tiap busur mempunyai anak panah dan bobot. Gambar 2.2 menunjukkan graf berarah dan berbobot yang terdiri dari tujuh titik yaitu titik A,B,C,D,E,F,G. Titik menujukkan arah ke titik B dan titik $C$, titik B menunjukkan arah ke titik D dan titik C, dan seterusnya. Bobot antar titik A dan titik B pun telah di ketahui. 


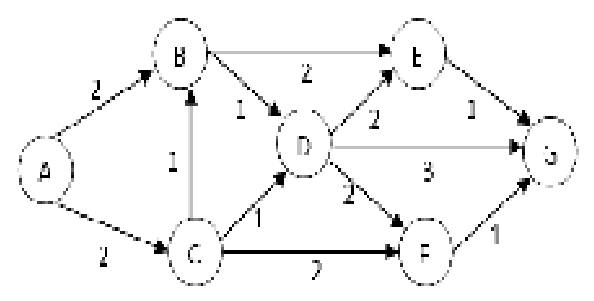

Gambar 2.2 Graf berarah dan berbobot

2. Graf tidak berarah dan berbobot : tiap busur tidak mempunyai anak panah tetapi mempunyai bobot. Gambar 2.3 menunjukkan graf tidak berarah dan berbobot. Graf terdiri dari tujuh titik yaitu titik A,B,C,D,E,F,G. Titik A tidak menunjukkan arah ke titik B atau C, namun bobot antara titik A dan titik B telah diketahui. Begitu juga dengan titik yang lain.

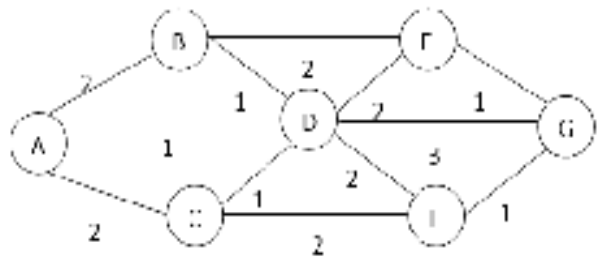

\section{Gambar 2.3 Graf tidak berarah dan berbobot}

3. Graf berarah dan tidak berbobot: tiap busur mempunyai anak panah yang tidak berbobot. Gambar 2.4 menunjukkan graf berarah dan tidak berbobot.

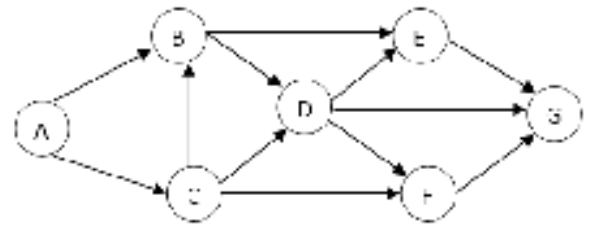

\section{Gambar 2.4 Graf berarah dan tidak berbobot}

4. Graf tidak berarah dan tidak berbobot: tiap busur tidak mempunyai anak panah dan tidak berbobot.

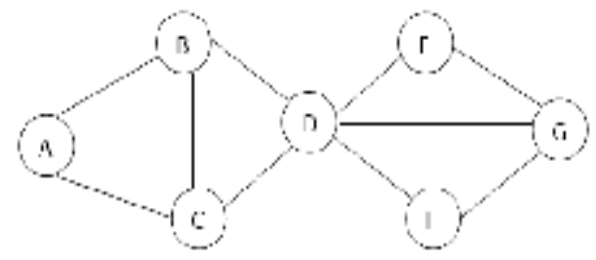

\section{Gambar 2.5 Graf tidak berarah dan tidak berbobot}

\subsubsection{Tree}

Tree merupakan struktur data yang mempunyai hubungan one to many. Hubungan one to many ini meliputi juga hubungan one to one atau one to zero, dapat dijelaskan bahwa satu parent bisa memiliki satu atau nol atau lebih dari satu child. Elemen dalam tree disebut dengan node.

Karakteristik dari treeadalah :

- $\quad$ Terdapat satu node yang unik, yang tidak memiliki predecessor. Node ini disebut root.

- $\quad$ Terdapat satu atau beberapa node yang tidak mempunyai successor. Node ini disebut leaf.

- $\quad$ Setiap node kecuali root, pasti memiliki satu predecessor yang unik. 
- $\quad$ Setiap node kecuali leaf, pasti memiliki satu atau lebih successor.

\subsection{Algoritma $A *$}

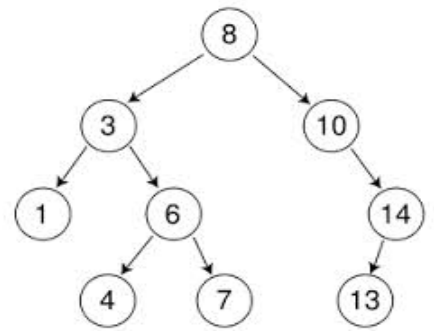

Gambar 2.6 Tree

Algoritma $\mathrm{A} *$ merupakan perbaikan dari metode best first search dengan memodifikasi fungsi heuristiknya, Algoritma A* akan meminimumkan total biaya lintasan. Pada kondisi yang tepat, Algoritma A* akan memberikan solusi yang terbaik dalam waktu yang optimal (Kusumadewi , 2003).

Fungsi $f(n)$ sebagai estimasi fungsi evaluasi terhadap noden, ditunjukkan oleh persamaan 2.1:

$$
f(n)=g(n)+h(n)
$$

dengan :

$f(n)=$ fungsi evaluasi

$g(n)=$ biaya yang sudah dikeluarkan dari

keadaan awal sampai keadaan $n$

$h(n)=$ estimasi biaya untuk sampai pada suatu tujuan mulai dari $n$

Pada Algoritma A*, dibutuhkan 2 antrian, yaitu :

- OPEN, yang berisi node-node yang sudah dibangkitkan, sudah memiliki fungsi heuristic namun belum diuji.

- CLOSED berisi node-node yang sudah di uji

\section{HASIL DAN PEMBAHASAN}

Adapun Software/Tools yang digunakan dalam pembuatan aplikasi pencarian jalur terpendek ini adalah :

1. AutoCAD 2010 : Menentukan cost/jarak sebenarnya antara dua node/titik yang berhubungan.

2. Google SketchUP 8 Pro : Desain denah dan gedung agar lebih menarik.

3. Adobe Flash Professional CS6 : Desain aplikasi dan koding.

\subsection{Analisis Masalah}

Algoritma $A^{*}$ (A-Star) merupakan suatu algoritma yang termasuk pada kategori metode pencarian yang memiliki informasi (informed search method). Algoritma $\mathrm{A}^{*}$ menggunakan estimasi jarak terdekat (cost/jarak sebenarnya) untuk mencapai tujuan (goal) dan memiliki nilai heuristik yang digunakan sebagai dasar pertimbangan pemilihan jalur. 
Adapun analisis algoritma $A^{*}$ yang akan dilakukan pada penelitian ini yaitu pada gambar 3.1 akan dicari jalur terpendek antara titik awal (titik S / gedung Delima) menuju ke titik tujuan (titik $\mathrm{T} /$ Gedung Asoka).

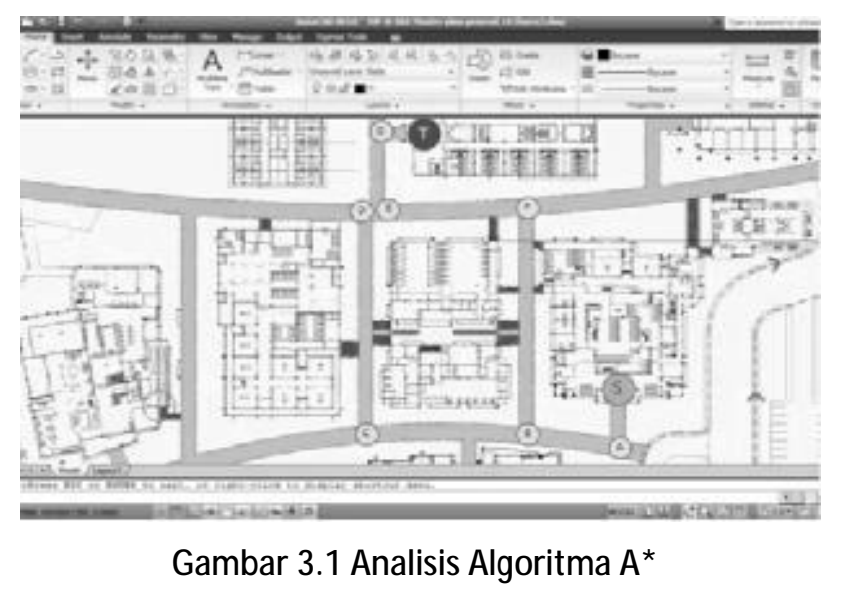

Untuk menyelesaikan permasalahan pencarian jalur terpendek dengan menggunakan Algoritma $\mathrm{A}^{*}$,maka langkah-langkah untuk flowchart Algoritma A* yang ditunjukkan oleh gambar 3.2.

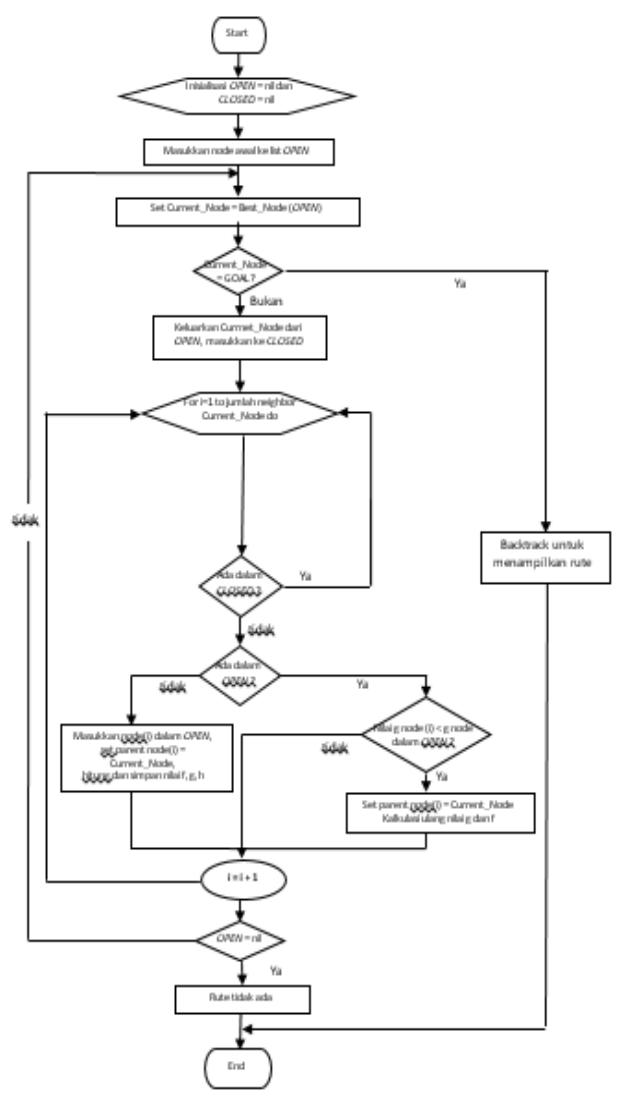

Gambar 3.2Flowchart Algoritma A* 
Adapun persamaan dari algoritma $\mathrm{A}^{*}$ ditunjukkan oleh persamaan :

Dimana:

$$
f(n)=g(n)+h(n)
$$

$f(n)=$ fungsi evaluasi node/titik $n$

$g(n)=$ cost yang sudah dikeluarkan dari node/titik awal sampai ke noden

$h(n)=$ estimasi biaya untuk sampai pada suatu tujuan mulai dari $n$

Untuk menentukan nilai $h(n)$ ditunjukkan oleh persamaan :

$$
h(n)=\sqrt{\left(X_{n}-X_{\text {goal }}\right)^{2}+\left(Y_{n}-Y_{\text {goal }}\right)^{2}}
$$

dimana :

$h(n)=$ nilai heuristic untuk node/titik $n$

$X_{n}=$ nilai koordinat xdari node/titik $n$

$Y_{n}=$ nilai koordinat ydari node/titik $n$

$X_{\text {goal }}=$ nilai koordinat $\mathrm{xdari}$ node/titik tujuan

$Y_{\text {goal }}=$ nilai koordinat ydari node/titik tujuan

\subsection{Penentuan cost/biaya antara dua node/titik yang berhubungan}

Untuk menentukan cost antara dua node yang berhubungan, akan dicari menggunakan fungsi Measurement pada autocad 2010. Hasil dari pengukuran nilai cost antara dua node yang saling berhubungan

a. cost node T ke node A dan sebaliknya adalah 14.10 meter

b. cost node A ke node B dan sebaliknya adalah 25.63 meter

c. costnode $\mathrm{B}$ ke node $\mathrm{C}$ dan sebaliknya adalah 45.48 meter

d. costnode $\mathrm{B}$ ke node $\mathrm{F}$ dan sebaliknya adalah 69.16 meter

e. costnode $\mathrm{C}$ ke node $\mathrm{D}$ dan sebaliknya adalah 67.12 meter

f. costnode $\mathrm{D}$ ke node $\mathrm{E}$ dan sebaliknyaadalah 4.17 meter

g. costnode $\mathrm{E}$ ke node $\mathrm{F}$ dan sebaliknya adalah 41.96 meter

h. costnode $\mathrm{E}$ ke node $\mathrm{G}$ dan sebaliknya adalah 23.08 meter

i. costnode $\mathrm{G}$ ke node $\mathrm{T}$ dan sebaliknya adalah 7.47 meter

\subsection{Penentuan koordinat setiap node/titik}

Untuk menentukan titik koordinat suatu node, denah pada autocad 2010 di export pada Google SketchUp 2014 kemudian dibuat ulang dan dimasukkan ke dalam aplikasi Adobe Flash CS6 dalam format jpg.

Adapun hasil penentuan titik koordinat setiap node/titik adalah sebagai berikut :

a. Koordinat nodeS $(371.85,322.05)$

b. KoordinatnodeA $(371.85,337.25)$

c. Koordinat nodeB $(340.35,331.90)$

d. Koordinat nodeC $(284.35,331.90)$ 
e. Koordinat node $D(284.35,248.50)$

f. Koordinat nodeE $(288.55,248.50)$

g. KoordinatNodeF $(340.25,246.80)$

h. KoordinatNodeG $(288.55,219.50)$

i. KoordinatNode $T(300.35,219.50)$

Tampilan (dalam bentuk graph) analisis algoritma A* setelah cost/biaya antara dua node yang berhubungan dan koordinat setiap node di tentukan ditunjukkan oleh gambar 3.3.

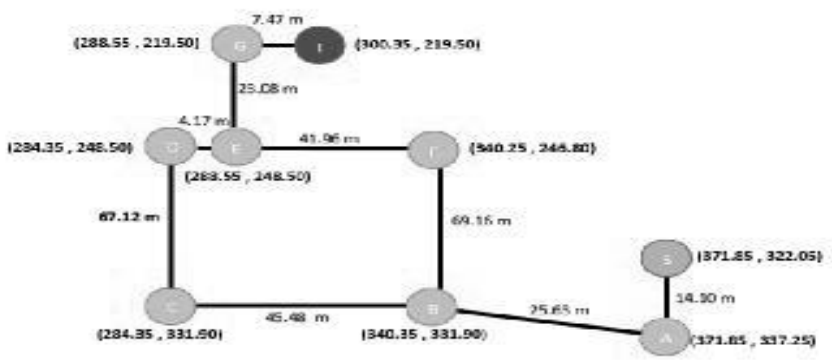

Gambar 3.3 Analisis Algoritma A* dalam bentuk graph

\subsection{Penentuan koordinat setiap node/titik}

Setelah mendapatkan nilai cost/biaya antara dua node yang berhubungan dan titik koordinat setiap node/titik, kemudian lakukan proses penghitungan nilai $f(n)$ dengan langkah-langkah sebagai berikut :

\section{Langkah 1}

- Set $O P E N=\{\}$

- Set CLOSED = \{\}

- Node Awal = S

- Node Tujuan= T

\section{Langkah 2}

- Masukkan node awal ke OPEN List

- OPEN $=\{\mathrm{S}\}$

- set Current_Node $=\{\mathrm{S}\}$

\section{Langkah 3}

- Periksa apakah Current_Node adalah node tujuan

- Current_Node (node S) bukan node Tujuan

- Karena node $\mathrm{S}$ bukan node tujuan, maka keluarkan node S dari OPEN dan pindahkan ke CLOSED

- $O P E N=\{\}$

- $C L O S E D=\{\mathrm{S}\}$

Langkah 4

- Hitung jumlah jalur yang bisa dilalui dari Current_Node (neighbornode S)

- Jumlah jalur yang bisa dilalui berjumlah 1 jaluryaitu jalur ke node A.

- Lakukan iterasi sebanyak 1 kali (for $\mathrm{i}=1$ to jumlah neighborCurrent_Node)

- Iterasi 1 dilakukan pada node A

- Periksa apakah node A ada di OPEN atau di CLOSED atau tidak berada di OPEN maupun CLOSED

- Node A tidak berada di OPEN maupun CLOSED, sehingga node A dimasukkan ke OPEN

- $O P E N=\{\mathrm{A}\}$

- Hitung nilai $g(A), h(A)$ dan $f(A)$

$$
g(A)=\text { costnode } \mathrm{S} \text { ke node } \mathrm{A}
$$




$$
\begin{aligned}
& g(A)=14.10 \text { meter } \\
& h(A)=\sqrt{(371.85-288.55)^{2}+(322.05-219.50)^{2}} \\
& h(A)=\sqrt{6983.89+10516.50} \\
& h(A)=156.47 \\
& f(A)=g(A)+h(A) \\
& f(A)=14.10+156.47 \\
& f(A)=170.57 \\
& \text { Nilai } f(A) \text { adalah } 170.57
\end{aligned}
$$

\section{Langkah 5}

- nilai $f(n)$ terkecil adalah nilai $f(A)$

- Current_Node $=\{\mathrm{A}\}$

\section{Langkah 6}

- Current_Node (node A) bukan node tujuan

- pindahkan node A dari OPEN ke CLOSED

- $O P E N=\{\}$

- $\operatorname{CLOSED}\{\mathrm{S}, \mathrm{A}\}$

\section{Langkah 7}

- Hitung jumlah jalur yang bisa dilalui dari Current_Node (neighbornode A)

- Jumlah jalur yang bisa dilalui adalah 1 yaitu ke node $\mathrm{B}$

- Lakukan iterasi sebanyak 1 kali (for $\mathrm{i}=1$ to jumlah neighborCurrent_Node)

- Iterasi 1 dilakukan pada node $\mathrm{B}$

- Periksa apakah node B ada di OPEN atau di CLOSED atau tidak berada di OPEN maupun CLOSED

- Node B tidak berada di OPEN maupun CLOSED, sehingga node B dimasukkan ke OPEN

- $O P E N=\{\mathrm{B}\}$

- Hitung nilai $g(B), h(B)$ dan $f(B)$

$$
\begin{aligned}
& \qquad g(B)=\mathrm{g}(\mathrm{A})+\text { cost node A ke node } \mathrm{B} \\
& \qquad g(B)=14.10 \text { meter }+25.63 \text { meter } \\
& g(B)=39.73 \text { meter } \\
& \qquad h(B)=\sqrt{(340.35-300.35)^{2}+(331.90-219.50)^{2}} \\
& h(B)=\sqrt{1600+12633.76} \\
& h(B)=\sqrt{14233.76} \\
& h(B)=119.30 \\
& f(B)=g(B)+h(B) \\
& f(B)=39.73+119.30 \\
& f(B)=159.03 \\
& \text { Nilai dari } f(B) \text { adalah } 159.03
\end{aligned}
$$

\section{Langkah 8}

- $O P E N=\{\mathrm{B}\}$

- Current_Node $=\{\mathrm{B}\}$

- Ulangi langkah-langkah diatas pada node-node lain dengan menggunakan aturan yang ada pada flowchart sampai didapatkan jalur terpendeknya. 
Adapun Hasil pencarian jalur terpendek menggunakan algoritma $\mathrm{A}^{*}$ berdasarkan perhitungan langkah-langkah di atas ditunjukkan oleh gambar 3.4.

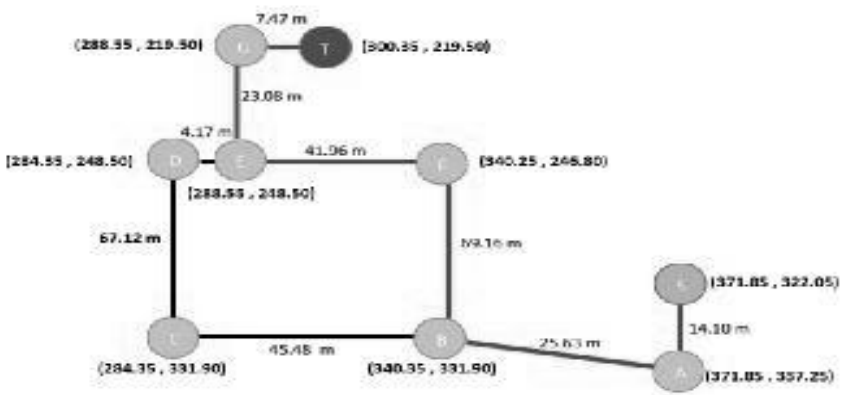

Gambar 3.4 Hasil analisis jalur terpendek menggunakan algoritma A*

Adapun implementasi pada smartphone adalah sebagai berikut :

\section{a. Form Menu Utama}

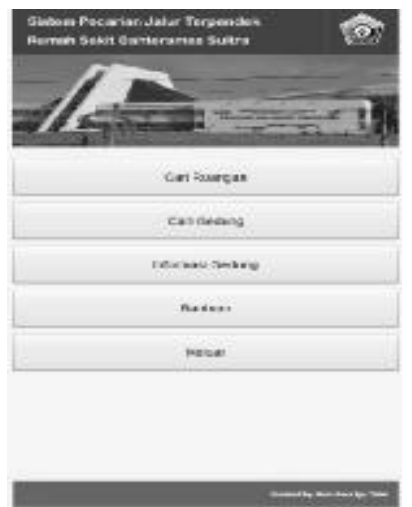

Gambar 3.5Form menu

Pada form ini user memilih menu yang akan dibuka sesuai kebutuhannya, terdapat 3 menu, yaitu: Cari Ruangan, Bantuan, dan Keluar.

\section{b. Form Cari Ruangan}

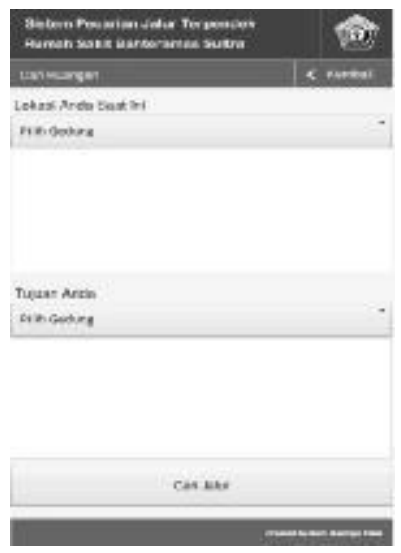

Gambar 3.6Form Cari Ruangan 
Pada form ini user menentukan posisi awal berupa posisi gedung beserta ruangan user saat ini berada dan menentukan posisi tujuan berupa gedung berserta ruangannya. Setelah menentukan posisi awal dan tujuan, tekan tombol Cari Jalur untuk melihat jalur terpendek antara gedung posisi awal dengan posisi gedung tujuan.

\section{c. Form hasil pencarian gedung}

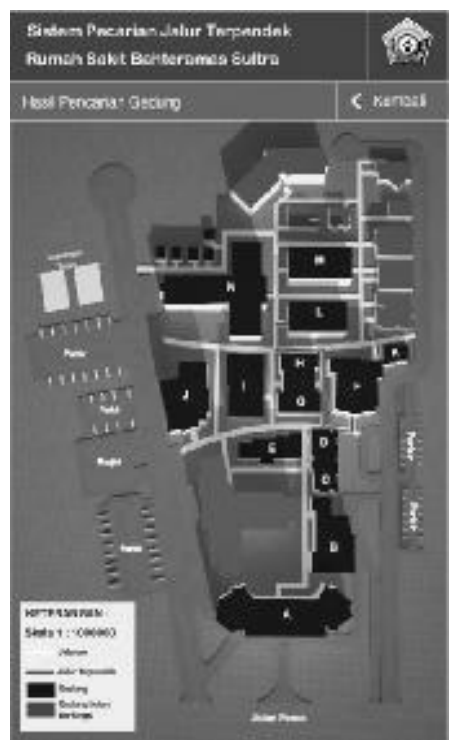

Gambar 3.7Form hasil pencarian gedung

Pada form ini akan ditampilkan jalur terpendek menuju gedung tujuan dari gedung posisi awal user. Untuk melihat jalur terpendek menuju ruangan, user dapat menekan gambar gedung tujuan.

\section{d. Form hasil pencarian ruangan}

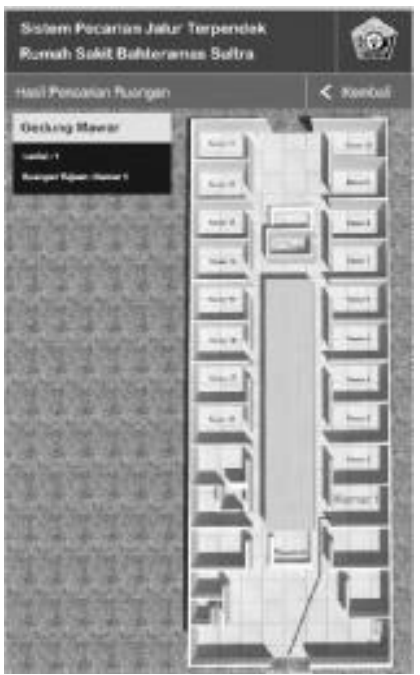

\section{Gambar 3.8Form hasil pencarian ruangan}

Pada form ini user dapat melihat jalur terpendek menuju ruangan tujuan dari pintu masuk gedung. 


\section{e. Form Cari Gedung}

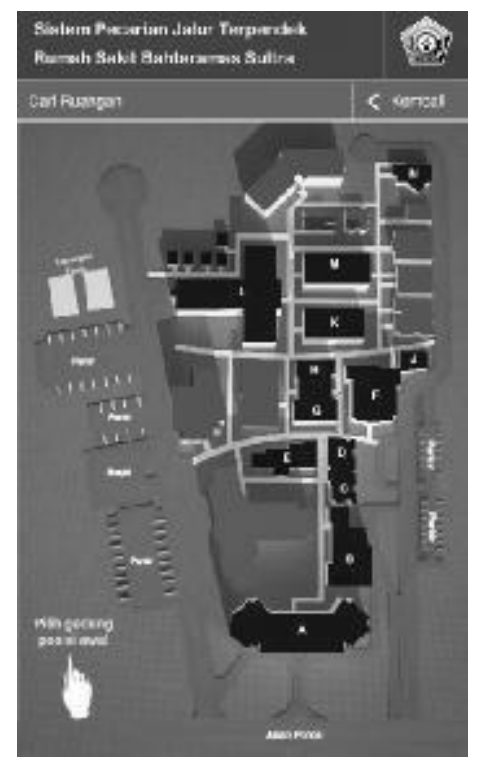

Gambar 3.9Form Cari Gedung

Pada form ini user dapat melihat jalur terpendek antara gedung posisi awal dengan gedung tujuan dengan cara menekan gambar gedung posisi awal dan gedung posisi tujuan.

\section{f. Form Informasi Gedung}

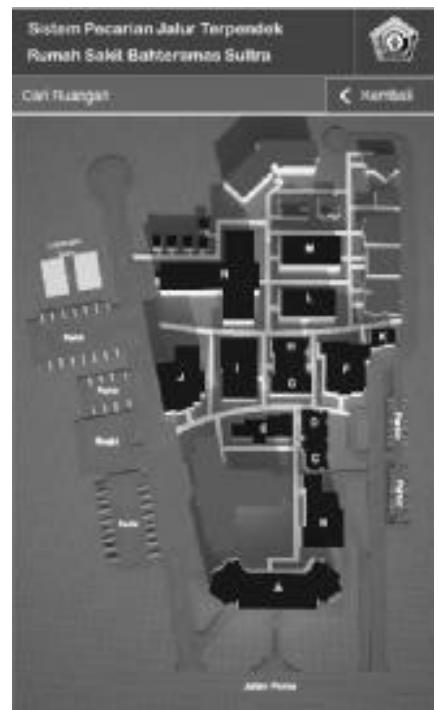

\section{Gambar 3.10Form Informasi Gedung}

Pada form ini user dapat melihat informasi dari gedung yang dipilih. 


\section{g. Form Bantuan}

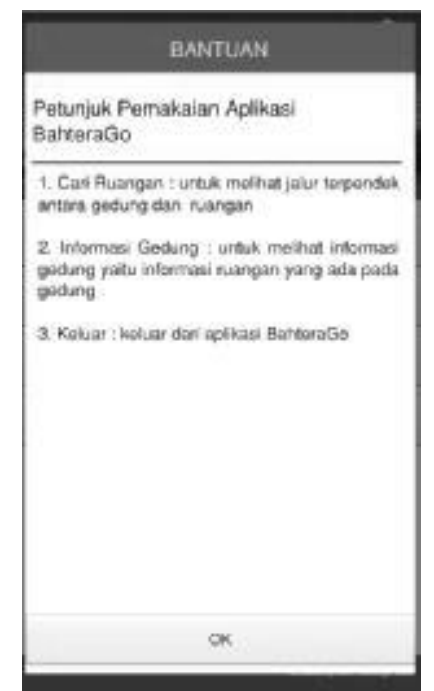

Gambar 3.11Form Bantuan

Pada form ini menampilkan petunjuk pemakaian dari aplikasi, sehingga memudahkan user untuk menggunakan aplikasi.

\subsection{Analisis Hasil}

Pada tahap ini akan dijelaskan analisis hasil kinerja dari aplikasi BahteraGo.

\subsubsection{Analisis Pencarian Jalur Terpendek Gedung}

Pada aplikasi BahteraGo, user terlebih dahulu menentukan posisi awal dan tujuan berupa gedung. Kemudian sistem akan menghitung jalur terpendek antara gedung menggunakan Algoritma A*. Contoh :

- Posisi gedung awal : Gedung Delima

- Posisi koordinat gedung awal : $(371.85,322.05)$

- Posisi gedung tujuan: Gedung Asoka

- Posisi Koordinat gedung tujuan $(300.35,219.50)$

- Total jarak terpendek : 181.40 meter

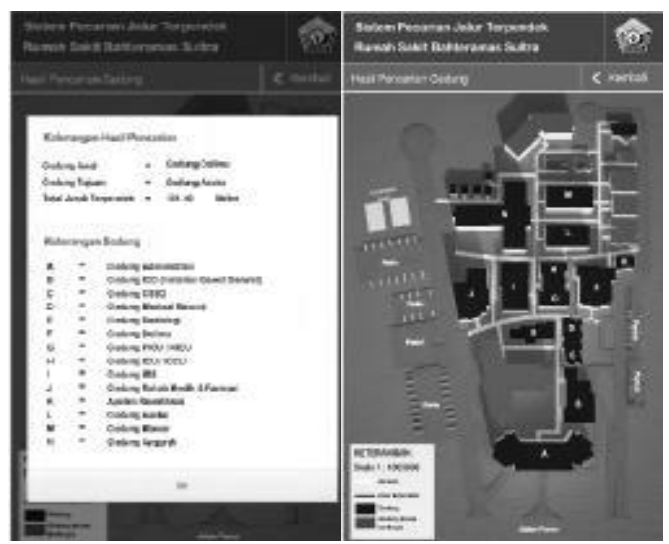

Gambar 3.12 Analisis pencarian jalur terpendek gedung 


\subsubsection{Analisis Pencarian Jalur Terpendek Ruangan}

Pada aplikasi BahteraGo, user terlebih dahulu menentukan posisi awal dan tujuan berupa ruangan. Kemudian sistem akan menghitung jalur terpendek antara pintu masuk gedung dengan ruangan yang dicari.

Contoh:

- Posisi awal dalam gedung Asoka : Pintu masuk gedung mawar

- Koordinat posisi awal : (304.40,640.45)

- Posisi tujuan dalam gedung Asoka : Kamar 1

- Koordinat posisi tujuan : $(300.05,161.50)$

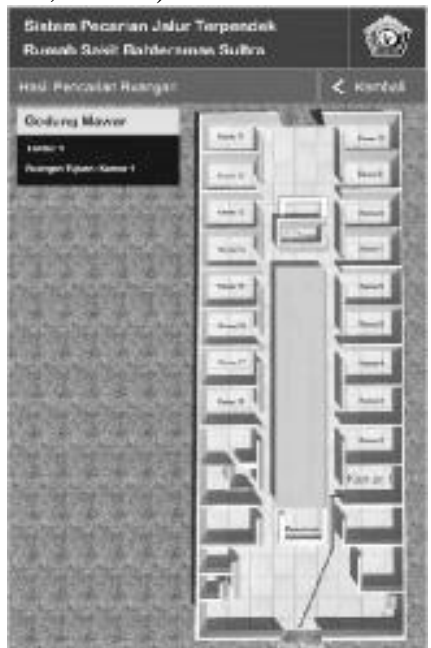

Gambar 3.13 Analisis hasil pencarian jalur terpendek ruangan

\section{KESIMPULAN}

Kesimpulan yang dapat diambil dari penulisan tugas akhir ini adalah sebagai berikut:

1. Untuk menentukan jalur terpendek pada pencarian ruangan dengan menggunakan algoritma $\mathrm{A} *(A-$ Star), dibutuhkan beberapa data yaitu, jarak sebenarnya antara node yang berhubungan (cost antar node) dan koordinat setiap node. Dengan data tersebut, maka pencarian jalur terpendek pada ruangan dapat diimplementasikan.

2. Aplikasi BahteraGo dibangun menggunakan aplikasi Adobe Flash Profesional CS6 dengan bahasa pemrograman actionscript 3 agar dapat diimplementasikan pada smartphone dengan operating system (OS) Android memanfaatkan fitur Adobe Air. 


\section{DAFTAR PUSTAKA}

Chambers, M., Dura, D., Georgita, D. dan Hoyt, K., 2008, Adobe AIR for JavaScript Developers Pocket Guide, O'Reilly Media Inc., Canada.

Champeaux, D. dan Sint, L., 1977, An improved bidirectional heuristic search algorithm, Journal of the ACM 24 (2):177-191, doi: $10.1145 / 322003.322004$.

Doran, J.E. dan Michie, D., 1966, Experiments with the Graph Traverser Program. Proc. Roy. Soc., Vol. 294, pp. 235-259.

Kusumadewi, S., 2003, Artificial Intelligence (teknik dan Aplikasinya), Graha Ilmu, Yogyakarta.

Mario, I. dan Aryo., 2004, Analisis Fungsi-Fungsi Heuristic Pada Algoritma Pathfinding A*, Skripsi S1 Universitas Bina Nusantara, Jakarta.

Patel, A.D., 2003, Amit's Thoughts on Pathfinding, Nature Neuroscience, 6, 674-681.

Pawitri, K., Ayu, Y. dan Joko, P., 2007, Implementasi Algoritma PHYSICAL-A* (PHA*) untuk menemukan Lintasan Terpendek, http://journal.amikom.ac.id/index.php/SN/article/view/2075, diakses 12 Juni 2014.

Pressman, R.S., 2001, Software Engineering : A Practitioner Approach, McGraw - Hill Companies.

Rossa, A.S., dan Shalahiddun, M. 2011, Rekayasa Perangkat Lunak (Terstruktur dan Berorientasi Objek), Modula, Bandung.

Rosenzweig, G., 2008, ActionScript 3.0 Game Programming University, Que Publishing, USA.

Russel, S. dan Peter, N., 1995, Artificial Intelligence A Modern Approach Second Edition, Pearson Education, Inc., New Jersey.

Wiitala, S.A., 1987, Discrete mathematics a unified approach, McGraw-Hill, New York.

Zakaria., 2006, Teknologi Informasi dan Komunikasi, Arya Duta, Jakarta. 